\title{
Colocalization within the Nucleolus of Two Highly Related IFN-Induced Human Nuclear Phosphoproteins with Nucleolin
}

\author{
G. I. Welsh, S. Kadereit, ${ }^{1}$ E. M. Coccia, ${ }^{2}$ A. G. Hovanessian, and E. F. Meurs ${ }^{3}$ \\ Unité de Virologie et d'I mmunologie Cellulaire, Institut Pasteur, 75724 Paris cedex 15, France
}

\begin{abstract}
We have previously reported the identification of two interferon (IFN)-induced CDNAs which code for two proteins, named 41 and 75, which have homology to a number of proteins involved in regulating gene expression. Here we establish that these cDNAs correspond to in vivo synthesized mRNAs. Expression of the 41 and 75 cDNAs, both in vitro and in vivo, generated proteins of 30 and $68 \mathrm{kDa}$, respectively. In a variety of mammalian cells, 41 and 75 were found to be located in the nucleus, with 41 being localized to the nucleolus, whereas 75, although it is mainly concentrated at the periphery of the nucleolus, is also found throughout the nucleoplasm. Treatment with interferon results in a translocation of $\mathbf{4 1}$ to the periphery of the nucleolus and it is in this region that the two proteins colocalize. 41 and 75 were found to colocalize with nucleolin but not with B23 or fibrillarin, three nucleolar proteins involved in ribosome synthesis. This colocalization was not affected by low concentrations of actinomycin D. In view of this and since 41 and 75 have homology to proteins involved in regulating gene expression, we suggest that, in association with nucleolin, they play a role in ribosome biogenesis.
\end{abstract}

\section{INTRODUCTION}

Protein kinase $R$ (PKR) is a serine/threonine kinase, which is induced by interferon and which is regulated by the concentration of double-stranded RNA in cells. It is known to play an important role in the antiviral and antiproliferative actions of interferon [1]. During the doning of PKR from a $\lambda$ gt11 library expressing IFN-induced oligo(dT)-primed CDNAs using PKR-specific polyclonal antibodies, an additional cDNA corresponding to a novel mRNA induced by both $\alpha$ - and $\gamma$-interferon was isolated. Further library screening selected two highly related

\footnotetext{
${ }^{1}$ Present address: Department of Hematology/Oncology, Case Western Reserve University, Cleveland, Ohio 44106.

${ }^{2}$ Present address: Laboratory di Virologia, Instituto Superiore de Sanita, 00161 Rome, Italy.

${ }^{3}$ To whom correspondence and reprint requests should be addressed at Unité de Virologie et d'I mmunologie Cellulaire, Dept. SIDA/Retrovirus, Institut Pasteur, 28, rue du Dr. Roux, 75724 paris Cedex 15, France. Fax: 3301406130 12. E-mail: emeurs@pasteur.fr.
}

cDNAs [2]. These cDNAs, referred to as 41 (1044 bp) and 75 (1540 bp) are highly homologous, displaying perfect homology over 612 bp but differing at both ends. In addition CDNA 75 contains an insertion of 150 bp which is highly homologous (66\% homology between the two sequences at the amino acid level) to a region common to both proteins. The sequence of the 41 cDNA contains an open reading frame of 744 bp corresponding to a polypeptide of 248 amino acids, while that of the 75 cDNA contains an open reading frame of 1224 bp corresponding to a polypeptide of 408 amino acids [2, and see Results].

Sequence analysis of the 41 and 75 proteins revealed that they are very hydrophilic and rich in basic amino acids and contain two nuclear localization motifs. They also contain several potential phosphorylation sites for different serine/threonine protein kinases [2]. Database searches using the 41 and 75 amino acid sequences showed that they contain regions which have partial homology with helix-loop-helix motifs of a family of minor groove DNA binding proteins [2]. New database searches have revealed that the C-terminal regions of 41 and 75 are very homologous to those of SP100B, LYSP100B, and SP140, members of the SP100 family of nuclear proteins, the role of which is unclear. The SP100 family of proteins colocalize in the nucleus with the promeolytic leukemia protein (PML) in structures known as nuclear bodies $[3,4]$.

Both 41 and 75 contain a single LXXLL motif, which has been identified as a signature sequence that mediates protein interaction with nuclear receptors and a KDWK or SAND domain, which is thought likely to be a DNA binding domain [5-7]. The KDWK or SAND domain is found in a number of nuclear proteins, including the Drosophilia transcriptional activator protein DEAF-1, a DEAF-1-related protein, NUDR, previously referred to as suppressin and which has been implicated in the negative regulation of immune cell activation, and the APECED polyglandular autoimmune protein AIRE-1, which is thought to be a transcription factor [6-9]. In contrast to 41,75 also contains a $\mathrm{C} 4 \mathrm{HC} 3$ zinc finger domain near its $\mathrm{C}$-terminus. Interestingly, a similar domain is found in a number of nuclear proteins involved in the regulation of gene expression $[10,11]$. Although the precise role of this 
domain is not clear, it may represent a protein/protein interaction domain as for the related LI M domain [12]. Alternatively, it has been suggested that this domain is involved in interactions with chromatin [10].

It should be mentioned here that 41 and 75 have been referred to as human nuclear phosphoprotein 1 and 2 (HNPP1 and HNPP2) by others $[4,6]$. However, we will name these proteins by their original screen numbers [2], until a functional definition can be found.

The homology of 41 and 75 to a number of nuclear proteins involved in the regulation of gene expression suggests that they may play a role in this process. Here we provide evidence for their expression in human cells and confirm their specific localization in the nucleus.

\section{MATERIALS AND METHODS}

Materials. The monoclonal antibody against HA (12AC5) was purchased from Boehringer Mannheim (Meylan, France), while the rabbit polyclonal anti-HA antibody was obtained from Santa Cruz Biotechnologies (Santa Cruz, CA). pcDNA 3.1/Myc-His- and pcDNA3.1N5-His-tagged expression vectors and monoclonal antibodies against V5 and Myc epitopes were obtained from I nvitrogen (NV Leek, The Netherlands). Anti-mouse, anti-rabbit, anti-goat, and anti-human polyclonal antibodies conjugated to either FITC or Texas red were obtained from Caltag (San Francisco, CA). Rabbit antiserum raised against a purified preparation of human nucleolin was generously provided by Drs. M. Erard and C. Faucher, Centre de Recherche de Biochimie et de Génétique Cellulaire du CNRS, Toulouse, France. A mouse monoclonal antibody directed against human nucleolin was a kind gift from Dr. R. Foisner, Institute of Biochemistry and Molecular Cell Biology, University of Vienna, Vienna, Austria. The human autoantibody directed against fibrillarin was kindly provided by Dr. D. Hernandez-Verdun, Institut J acques Monod, Université Paris VII, Paris, France [13]. Actinomycin D was obtained from P-L Biochemicals Inc. (Milwaukee, WI).

Construction of tagged 41 and 75 expression vectors. 41 and 75 cDNA were excised from pcDNA1/neo [2] by HindlII and Xhol digestion and subcloned into pcDNA1/amp between the Hindl II and Xhol sites of the polylinker.

HA-tagged 41 was prepared as follows. The HA tag from pAS1CYH2 (Clontech) was excised by EcoRI and BamHI digestion and subcloned into the plasmid pSG5 (Stratagene) between the EcoRI and BamHI sites of the polylinker. The 41 cDNA was copied from pcDNA1/amp/41 by PCR using a 5' sense primer (GGGGGACATGGCGAGCAGCGGAGTC), corresponding to the start of the 41 coding region, with the addition of nucleotides to reconstruct a Sma site, at the $5^{\prime}$ end, and a $3^{\prime}$ antisense primer (ACCCTCTCAGTCACCATGTT), corresponding to the $3^{\prime}$ end of the 41 CDNA coding region. This PCR product was subcloned into the PSG5HA plasmid described above in the Sma site to give pSG5/HA-41.

To prepare pcDNA 3.1/41/Myc-His and pcDNA 3.1/41/N5-His, the 41 cDNA was copied from pcDNA1/amp/41 by PCR using the $5^{\prime}$ sense primer (GGATGAATTCTTCTTCTCCAATGTC) and the $3^{\prime}$ antisense primer (ACCGCGGGCCCTCCTTGCTATTTAA). The first 10 nucleotides of the $5^{\prime}$ primer correspond to the sequence surrounding the EcoRI site in pcDNA 3.1/Myc-His and pcDNA 3.1/N5-His (Clontech) and the other 15 correspond to the $\mathrm{M}$ bol I site (nucleotides 74- 88) of the 41 cDNA. The first 13 nucleotides of the $3^{\prime}$ antisense primer correspond to the sequence surrounding the Apal in pcDNA 3.1/Myc$\mathrm{His}$ and pcDNA 3.1N5-His and the rest corresponds to the region of the 41 cDNA just prior to the stop codon (nucleotides 943-954). The PCR product was digested with EcoRI and Apal and subcloned into the Myc-His and V5-His expressing pcDNA plasmids between the
EcoRI and Apal sites of the polylinker using version B of the vector so that the 41 cDNA was in phase with the tag.

To prepare pcDNA 3.1/75/Myc-His and pcDNA 3.1/75/N5-His, two primers, which correspond to the sense and antisense sequences at the $3^{\prime}$ end of 75 immediately prior to the stop codon (nucleotides 13561393), plus an Xhol site were synthesized: (ATGCAGCCTCAGGACCAGCTGAATGTGAGTTCCTCCTCTGGCCGCTCGAGT and ACTCGAGCGGCCAGAGGAGGAACTCACATTCAGCTGGTCCTGAGGCTGCAT). Thirty micrograms of each of the two primers was annealed in a final volume of $50 \mu$ l containing $10 \mathrm{mM}$ Tris- $\mathrm{HCl}, \mathrm{pH} 7.5,0.5 \mathrm{mM}$ $\mathrm{MgCl}_{2}$, and $50 \mathrm{mM} \mathrm{NaCl}$ by heating at $90^{\circ} \mathrm{C}$ for $5 \mathrm{~min}$ and then cooling slowly to ambient temperature. The annealed primers were then digested with Bsu36l and Xhol and subcloned into pcDNA1/amp/75 which had also been digested with these enzymes. This results in a 75 cDNA which lacks a stop codon at its $3^{\prime}$ untranslated region. This CDNA was then excised by HindlII and Xhol digestion and subcloned into pcDNA 3.1/Myc-His and pcDNAN5-His version B between the Hindl II and Xhol sites of the polylinker so that the 75 CDNA was in phase with the tag. The 75 construct as such corresponded to a truncated form of 75 lacking the first 37 amino acids (see Results). To restore the full coding sequence of 75 , the $5^{\prime}$ end of the original cloned insert was excised by BamHI from the Bluescript vector [2] and inserted at the BamHI sitein pcDNA 3.1/Myc-His and pcDNA 3.1N5-His.

In vitro translation. Transcription/translation reactions were carried out using the TNT T7 Quick Coupled Transcription/ Translation System (Promega) as described in the manufacturer's instructions.

Polysomal RNA analysis. U937 cells were treated for $24 \mathrm{~h}$ with $500 \mathrm{U} / \mathrm{ml}$ of human $\alpha$-interferon (lymphoblastoid IF N; Hayashibara Biochemicals Lab, J apan). Polysomal RNA was prepared and analyzed as described [14]. Probes specific for CDNA 41 and 75 were obtained by restriction digest from their nonhomologous $3^{\prime}$ end with Styl-EcoRI (166 bp) and Pstl-EcoRI (236 bp), respectively. Probes specific for actin or 6-16 were prepared as described [14].

RT-PCR. Total cytoplasmic RNA was prepared from IFN $\gamma$ treated HeLa cells with the acid guanidinium isothiocyanate/phenol chloroform method [15] using RNA-PLUS (Bioprobe). The RNA was treated for $30 \mathrm{~min}$ at $42^{\circ} \mathrm{C}$ with an excess of RNase-free DN ase before the DN ase was inactivated by heating at $70^{\circ} \mathrm{C}$ for $10 \mathrm{~min}$. Oligo(dT)primed first-strand synthesis was carried out as described [16]. A sixth of the first-strand synthesis reaction was submitted to PCR amplification using primers specific for the full-length 41 or 75 (41, sense 5'-GCGAGCAGCGGAGTCAAG-3', antisense 5'-CTTGCTATTAACTCTCTCT-3'; 75, sense 5'-GCCCCACTCTCCCTTGGGCT-3', antisense 5'-GAGGAGGAACTCACATTCAG-3'). In addition, in the case of 75 , one PCR reaction was carried out using a $5^{\prime}$ primer corresponding to a sequence in its insertion region (5'-GTAACTCCACGGTAGAGACAA- $3^{\prime}$ ) chosen to diverge the most from the $68 \%$ homol ogous downstream region. The products from the PCR reaction were analyzed by agarose gel electrophoresis. Since products from the reaction were not visible, the agarose gels were Southern blotted using 41 and 75 cDNA as probes [16].

Transfection. For transfection experiments HeLa or COS cells were seeded at $10^{4}$ cells $/ \mathrm{cm}^{2}$ in appropriate tissue culture dishes. After $24 \mathrm{~h}$ the cells were transfected by a calcium phosphate precipitation technique followed by glycerol shock [17].

Cell extraction. Cytoplasmic and nuclear cell extracts were pre pared $48 \mathrm{~h}$ after transfection of 10-cm-diameter tissue culture dishes by extracting the cells with a buffer containing $10 \mathrm{mM}$ Tris- $\mathrm{HCl}, \mathrm{pH}$ 7.6, $0.1 \mathrm{M} \mathrm{NaCl}, 1 \mathrm{mM}$ EDTA, $100 \mathrm{U} / \mathrm{ml}$ aprotinin, $0.1 \mathrm{mM} \mathrm{PMSF}$, and $0.05 \%(\mathrm{v} / \mathrm{V}) \mathrm{NP}-40$. The extracts were centrifuged at $400 \mathrm{~g}, 4^{\circ} \mathrm{C}$, to pellet the nuclei. The cytoplasmic fraction was removed and centrifuged at $12,000 \mathrm{~g}$ to remove cell debris. The nuclear pellet was extracted with a buffer containing $20 \mathrm{mM}$ Tris- $\mathrm{HCl}, \mathrm{pH} 7.6,50 \mathrm{mM} \mathrm{KCl}, 400 \mathrm{mM} \mathrm{NaCl}$, $1 \mathrm{mM}$ EDTA, 1\% Triton X-100, 20\% glycerol, $5 \mathrm{mM}$ mercaptoethanol, $100 \mathrm{U} / \mathrm{ml}$ aprotinin, and $0.2 \mathrm{mM}$ PMSF and centrifuged at $12,000 \mathrm{~g}, 4^{\circ} \mathrm{C}$ to remove debris. The extracts were analyzed on SDS-PAGE followed by Western blotting with appropriate antibodies. 
Confocal microscopy. For laser scanning confocal microscopy experiments, HeLa or COS cells were transfected in 8-well chamber slides (Labtek). At $24 \mathrm{~h}$ after transfection the cells were fixed with paraformal dehyde and lysed with $0.5 \%$ Triton X-100 in order to keep the integrity of the cellular structures. They were then stained with appropriate antibodies as described previously [18]. Primary antibodies were diluted 1/100 prior to use. Anti-mouse antibodies linked to FITC or Texas red and anti-rabbit antibodies also linked to either FITC or Texas red (Caltag) were also diluted 1/100 prior to use. Where appropriate, HeLa cells were treated with 500 units $/ \mathrm{ml} \alpha$-or $\gamma$-interferon for $24 \mathrm{~h}$ (added $4 \mathrm{~h}$ prior to transfection). For treatment with actinomycin D, either 0.05 or $5 \mu \mathrm{g} / \mathrm{ml}$ was added for $30 \mathrm{~min}$. The actinomycin was then removed and the cells were washed and then left in fresh medium for $8 \mathrm{~h}$ prior to fixation and lysis. The localization of 41 and 75 was analyzed using laser scanning confocal microscopy (Leica TCS4D machine). Green and red fluorescence were collected simultaneously and then separated digitally. Colocalization of proteins results in a merging of red and green fluorescence to produce a yellow image.

\section{RESULTS}

The 41 and 75 cDNAs Correspond to in Vivo Synthesized mRNAs

Expression of proteins from the cloned 41 and 75 cDNAs either in baculovirus-infected insect cells or in

41

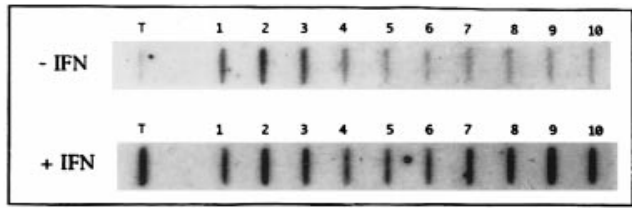

75
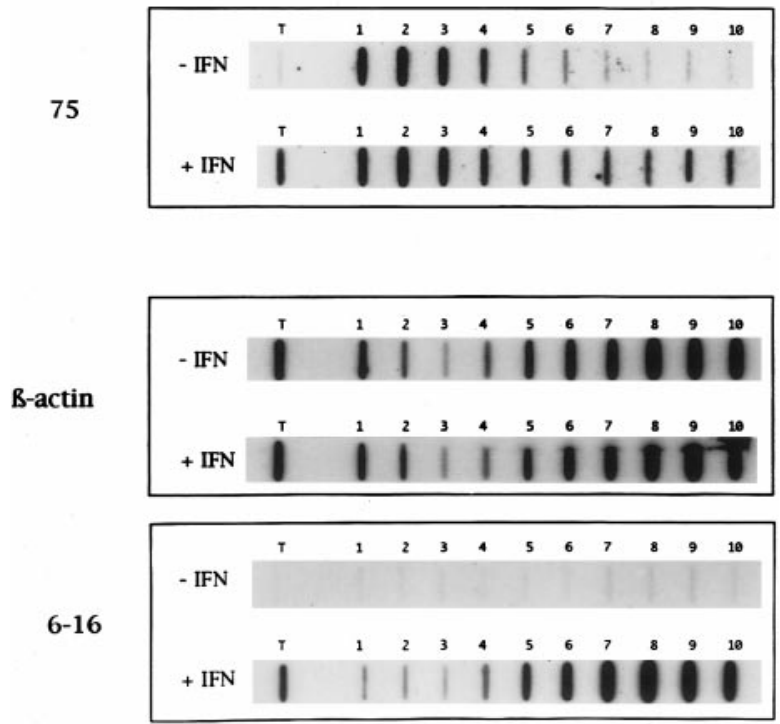

FIG. 1. Polysomal profiles of the mRNAs corresponding to CDNA 41 and 75. Extracts from control ( - IFN) and IF $\alpha$-treated (+IFN) U 937 cells were fractionated on sucrose gradients and the different fractions containing the ribosomal and polysomal mRNAs were transferred by the slot blot technique onto a nitrocellulose membrane and hybridized with specific radiolabeled probes for CDNA 41, $75, \beta$-actin, and the interferon-induced $6-16$ gene. Polysomal RNA were found in fractions $4-10$, the smallest polysomes being associated with fraction 4. Samples 1-3 contain monosomes and ribosomal subunits. Sample T contains the total cytoplasmic RNAs.
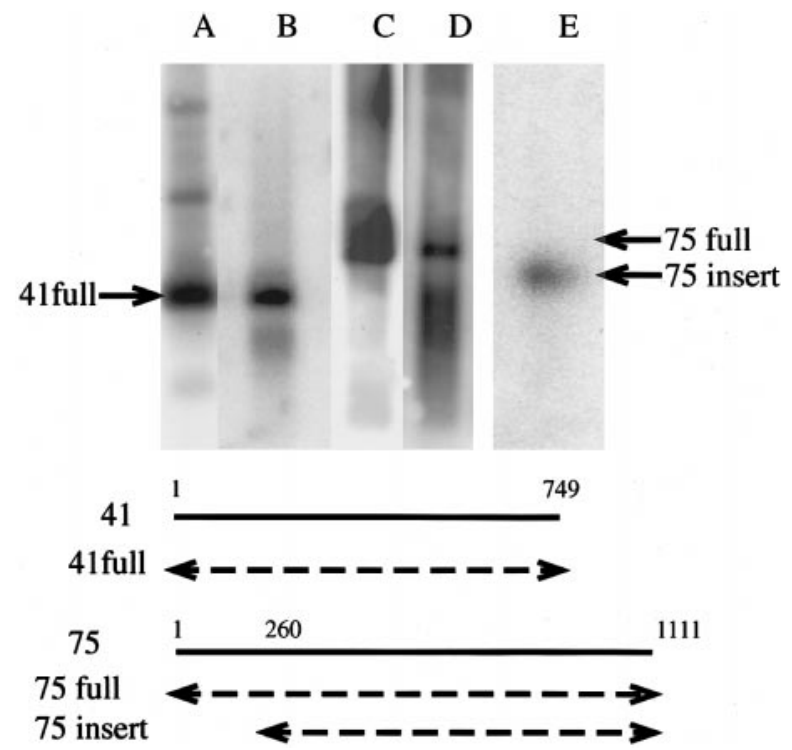

FIG. 2. RT-PCR analysis of in vivo expressed endogenous 41 and 75 mRNAs. RNA extracted from IF N $\gamma$-treated HeLa cells was analyzed by RT-PCR for the presence of 41 and 75 mRNAs. A and C represent PCR controls performed on 41 and 75 CDNAs from pCDNA/ amp vectors. B and D represent RT-PCR for 41 and 75, respectively. E represents RT-PCR for 75 using a 5 '-end primer starting in the 75 insert domain. The PCR products were separated on $1.2 \%$ agarose gels and a Southern blot of the gel is presented.

Escherichia coli from GST fusion proteins resulted in highly insoluble products (data not shown). For this reason, we could not purify these proteins to raise specific antibodies. Furthermore, the attempt to use antipeptide antibodies raised against regions located in the nonhomologous C-terminal ends of 41 and 75 has also so far been unsuccessful. In a previous study, we have shown by run-on analysis, using a cDNA probe corresponding to a sequence common to both 41 and 75, that they were rapidly induced by interferon at the transcriptional level and that this transcription was not dependent on continuous protein synthesis [2]. In order to verify that these proteins are produced in intact cells under physiological conditions, we investigated the expression of the mRNA of 41 and 75 and their association with polysomes. The polysomal distribution pattern of mRNAs may help to differentiate between translated and untranslated species since association of mRNA with high-molecular-weight polysomes is considered to reflect the translational activity of a given mRNA [14]. Gradient fractions of polysomal RNA from control and IFN-treated human U937 cells were transferred onto membrane and hybridized with probes specific for the nonhomologous $3^{\prime}$ end of CDNA 41 or 75 . As shown in Fig. 1, in the absence of IF N treatment the majority of the mRNAs corresponding to CDNA 41 and 75 are found in the subpolysomal/monosomal fractions (fractions 1-4). Following IFN treatment, a shift in the distribution of both mRNAs was 


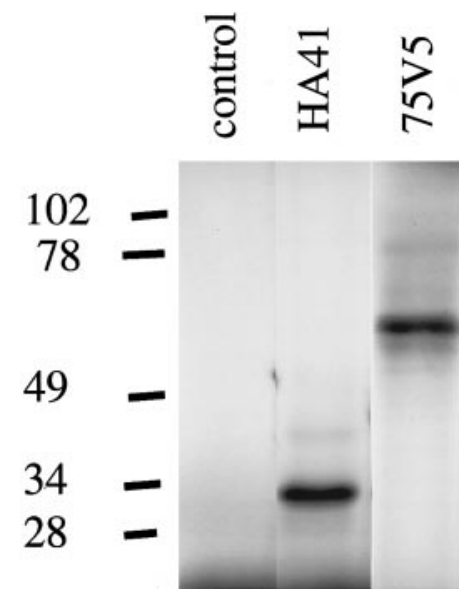

FIG. 3. In vitro expression of the tagged 41 and 75 constructs. Forty microliters of rabbit reticulocyte lysates (TNT kit; Promega) was incubated as such (control), with $4 \mu \mathrm{g}$ of a luciferase expressing vector (provided with the kit), or with pcDNA/Amp-HA-41 or pcDNA3.1-75-V5. The transcription/reaction was carried out for 90 min at $30^{\circ} \mathrm{C}$ in the presence of $5 \mu \mathrm{Ci}$ of $\left[{ }^{35} \mathrm{~S}\right]$ methionine/cysteine (Promix; Amersham). The ${ }^{35} \mathrm{~S}$-labeled proteins were analyzed by SDS-PAGE on $12.5 \%$ acrylamide gels.

observed. They were now also found to be associated with the polysomes of high molecular weight (fractions 4-10). Identical patterns of polysomal distribution for 41 and 75 were observed with polysome preparations from HeLa and CEM cells (data not shown). These results establish that 41 and 75 cDNAs correspond to in vivo synthesized mRNAs that can be associated with high-molecular-weight polysomal complexes, thus suggesting that both mRNA species become translated into proteins in vivo. In addition, these results confirm that both 41 and 75 are induced by interferon, consistent with our previous data [2]. Interestingly, some differences between the polysomal distribution of 41 and 75 mRNAs compared to that of $\beta$-actin or the interferon-induced 6-16 mRNAs used as controls in this experiment are observed (Fig. 1). Whereas both actin and 6-16 are progressively charged on the ribosome, a fraction of 41 and 75 mRNAs remains associated with low-molecular-weight polysomes. This may represent a mechanism of translational regulation, similar to that of ribosomal proteins, in which a pool of mRNAs is kept associated with low-molecular-weight polysomes in order to be immediately available for translation following stimulation [19]. It should be noted here, however, that the true identity (preexisting or newly synthesized) of the 41 and 75 mRNAs associated with low-molecular-weight polysomes could not be determined in this assay and would therefore require further analysis.

We have next confirmed that the 41 and 75 cDNAs correspond to in vivo synthesized mRNAs by carrying out RT-PCR analysis on RNA extracted from IF N-treated HeLa cells using primers specific for 41 and 75. As shown in Fig. 2, RT-PCR-generated DNA products migrating at the expected sizes were obtained for both 41 and 75 (Fig. 2, Ianes B and D). As mentioned previously the cDNA of 75 contains an insertion of $150 \mathrm{bp}$ which is highly homologous to a region common to both 41 and 75 . The nature of the 75 insert is somewhat intriguing. This insert, coding for 50 amino acids, resembles a duplication of a domain present downstream on the 75 sequence but sharing only $68 \%$ homology with this region. This discrepancy might indicate that, during evolution, a divergence had occurred between two motifs of the same protein. In order to determine that the two motifs are indeed present on the same protein and to rule out any possible artifact, we performed a PCR using a 5' primer specific to this insert, instead of the $5^{\prime}$ terminal primer. The resulting PCR product migrated in the gel as a band of the expected size (851 bp compared with 1111 bp for 75; Fig. 2, Ianes D and E). Therefore, the 50 -amino-acid insert of 75 protein is indeed an intrinsic part of the protein. Whether the sequence divergence between this insert and region A corresponds to a Darwinian positive selection or to an accumulation of random mutations is not known [20]. However, in favor of the first possibility, we had previously noted that the differences appearing in the 50-amino-acid insert allowed the generation of an additional potential phosphorylation motif, which may be of functional importance for the protein [2].

(A)

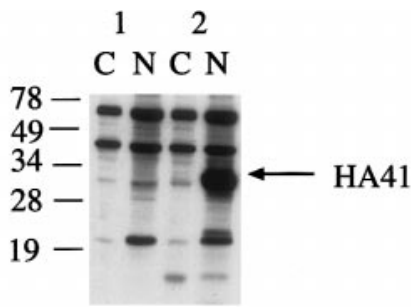

(B)

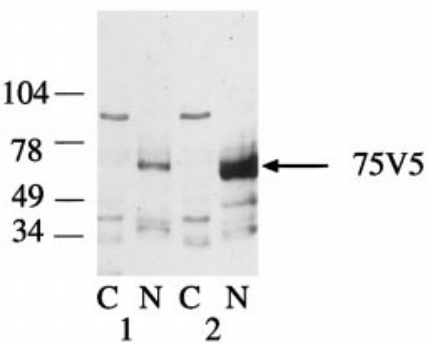

FIG. 4. Association of transfected tagged 41 and 75 with the nuclear fraction. COS cells were mock transfected (1) or transfected (2) with pcDNA/Amp-HA-41 (A) or with pcDNA3.1-75-V5 (B). Transfection was performed by the calcium phosphate technique using 20 $\mu \mathrm{g}$ of plasmid/100-mm petri dish. Cytoplasmic (C) and nuclear (N) fractions were prepared as described under Materials and Methods. Expression of HA-41 and 75-V5 was detected by immunoblotting with the use of anti-HA and anti-V5 antibodies after separation of the proteins by SDS-PAGE on $12.5 \%$ acrylamide gels. 
(A)

41

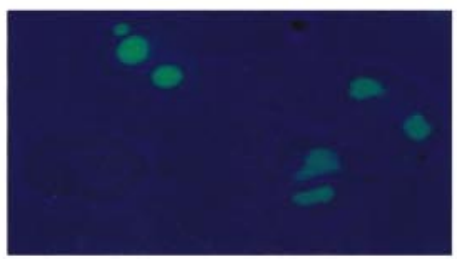

IFN

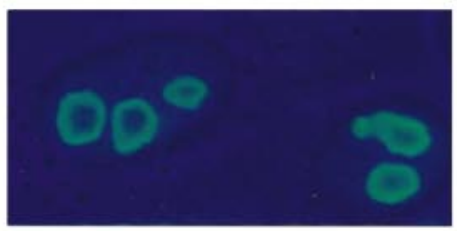

(B)

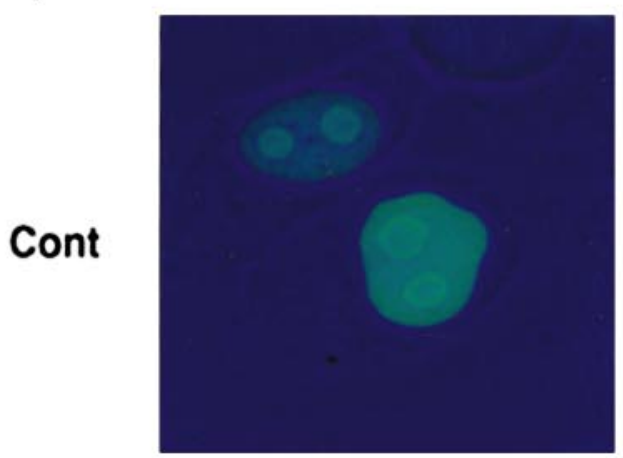

75

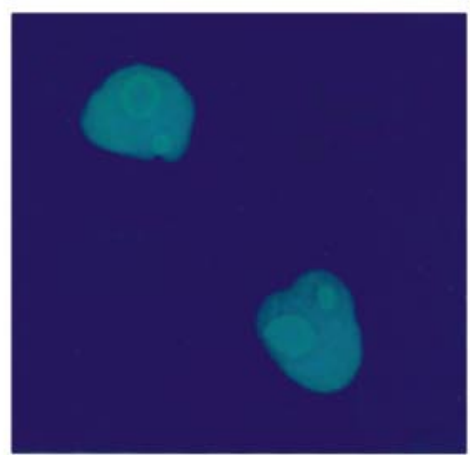

IFN

(C)

41

75

$41 / 75$

Cont
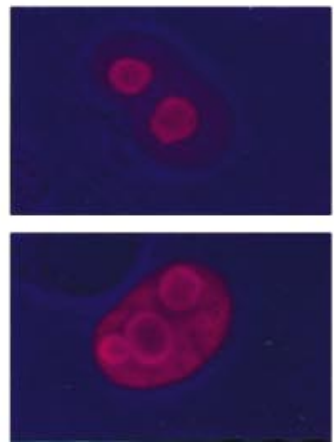

phase contrast
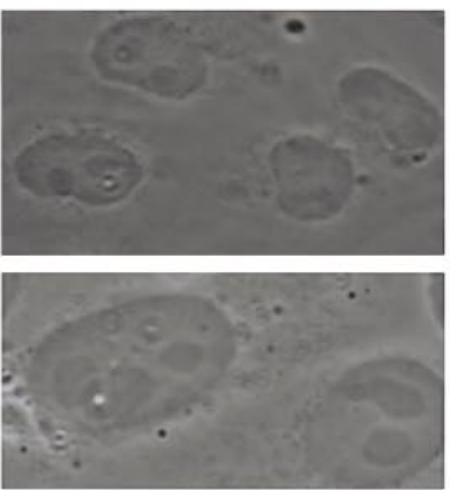

phase contrast
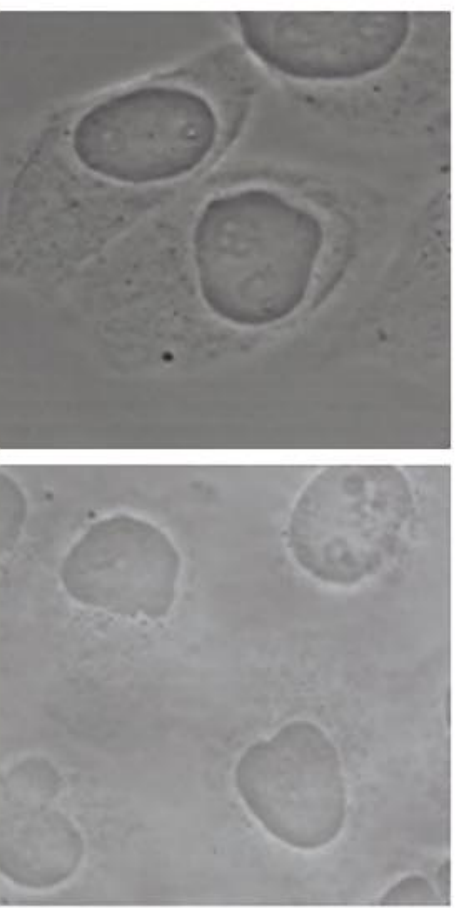

IFN
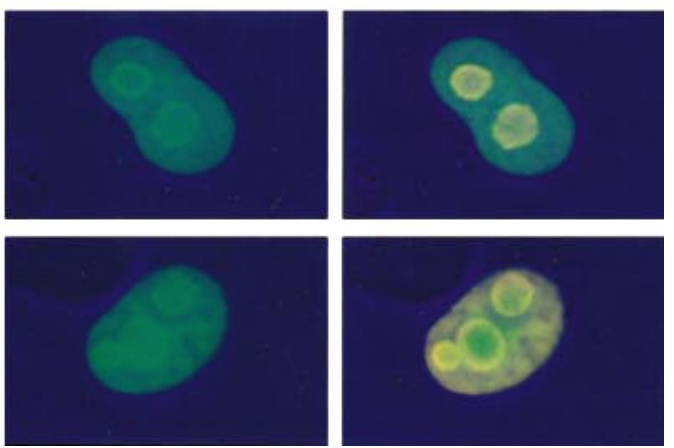
In Vitro and in Vivo Expression of 41 and 75 Proteins from Tagged Constructs

In order to characterize the expression of these proteins in cells, the 41 and the 75 proteins were tagged either N-terminally with HA or C-terminally with the MYC or V5 epitope. It should be noted here that during the preparation of the tagged constructs, the original 75 full-length CDNA obtained by screening [2] was resequenced and found to contain an additional $C$ at position 201 which had been previously missed during manual sequencing at the time of the cloning. This causes an apparent frameshift and in fact, the coding sequence of 75 is longer by 37 amino acids than previously described (methionine start at nucleotide 171 instead of 281; for correction, see Accession No. L22343 in GenBank). Therefore, the pcDNA/Amp/75-V5 was engineered to contain the full $5^{\prime}$ end of 75 . The transcription/translation of the tagged constructs using the TNT T7 Quick Coupled Transcription/Translation System (Promega) revealed a size of about $30 \mathrm{kDa}$ for 41 , as previously described [2], and around $68 \mathrm{kDa}$ for 75 (Fig. 3). The latter size corresponds now to the size for 75 observed after expression in insect cells from a baculovirus-derived vector since this construction was made using the original 75 insert, whereas a size of 50 $\mathrm{kDa}$ was observed when in vitro translation was performed from a pcDNA/Neo (75) construct which was truncated from its first 229 nucleotides [2]. I nitial attempts to analyze in vitro translated tagged 41 or 75 using immunoprecipitation or Western blotting were

FIG. 5. Localization of 41 and 75 in transiently transfected HeLa cells: effect of interferon. Laser scanning confocal microscopy was carried out on untreated (Cont) or interferon-treated (IFN) HeLa cells transiently transfected with either $41 \mathrm{~V} 5$ (A) or 75V5 (B) or with HA41 and 75V5 (C). The cells were fixed in paraformaldehyde and lysed with $0.5 \%$ Triton X-100 in order to keep the integrity of the cellular structures [18]. The cells were then stained with mouse anti-V5 (A and B) or rabbit anti-HA and mouse anti-V5 (C) followed by anti-mouse IgG coupled to FITC (green fluorescence) (A and B) or anti-mouse IgG coupled to FITC (green fluorescence) and anti-rabbit IgG coupled to Texas red (red fluorescence) (C). For A and B phasecontrast pictures are shown. For C red fluorescence (HA41) and green (75V5) were collected simultaneously and then separated digitally. Colocalization of proteins results in a merging of red and green fluorescence to produce a yellow image.

FIG. 6. Comparison of the localization of $41 / 75$ and with fibrilIarin and B23/nucleoplasmin in transiently transfected HeLa cells. Laser scanning confocal microscopy was carried out on untreated (Cont) or interferon-treated (IFN) HeLa cells which had been transiently transfected with HA41 (A and C) or 75V5 (B or D). For A and $B$ the cells were stained with human anti-fibrillarin and with either mouse anti-HA antibody (A) or mouse anti-V5 antibody (B). This was followed by anti-human IgG coupled to FITC (green fluorescence) and anti-mouse IgG coupled to Texas red (red fluorescence). For C and D the cells were stained with goat anti-B23 antibody and with either mouse anti-HA antibody (C) or mouse anti-V5 antibody (D). In each case red fluorescence (HA41 or 75V5) and green (fibrillarin or B23) were collected simultaneously and then separated digitally. Colocalization of proteins results in a merging of red and green fluorescence to produce a yellow image. The pictures show whole cells but in each case only the nucleolus or nucleus of the cell is stained.
(A)

41

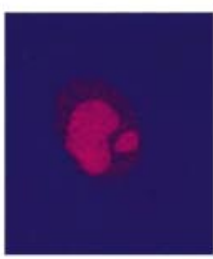

IFN

(B)

Cont

IFN

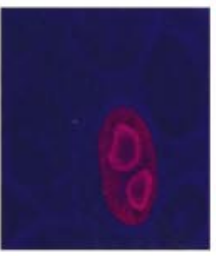

75
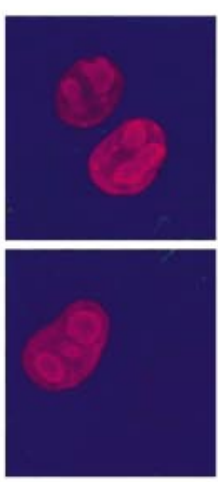

(C)
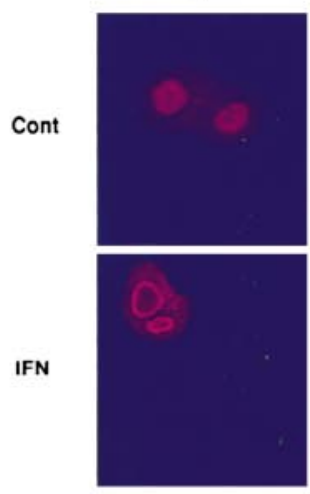

75

(D)

Cont
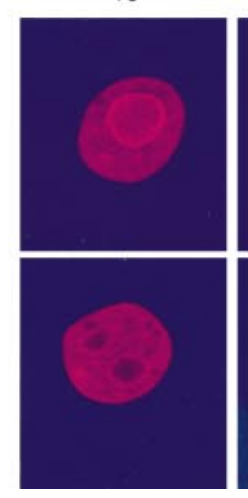

fibrillarin
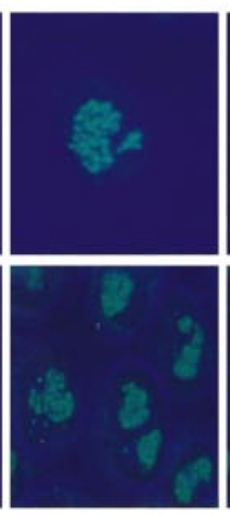

fibrillarin
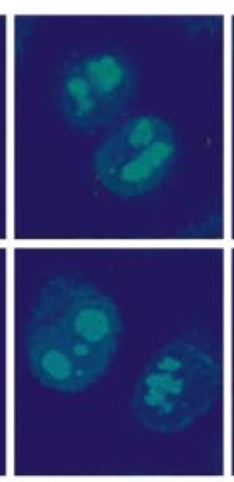

P.

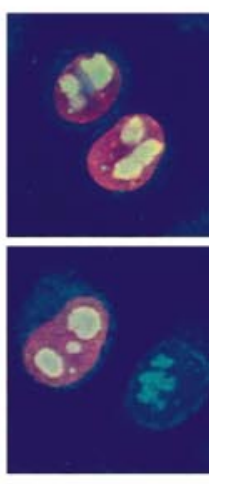

$41+$ fibrillarin

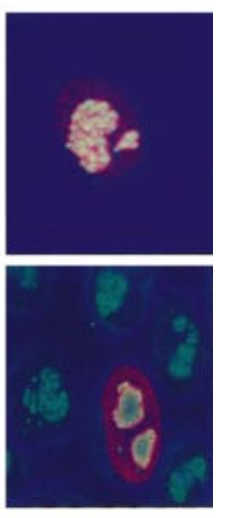

$75+$ fibrillarin
B23
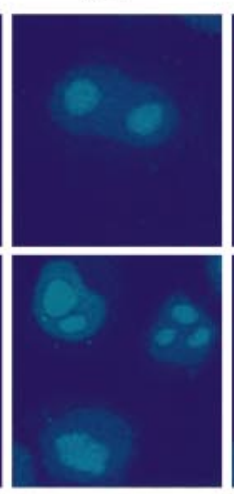

B23

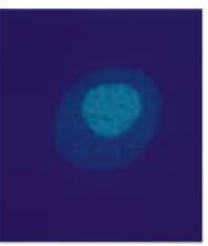

41/B23
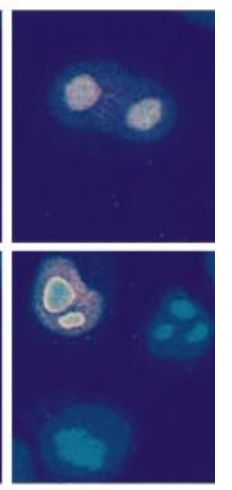

75/B23

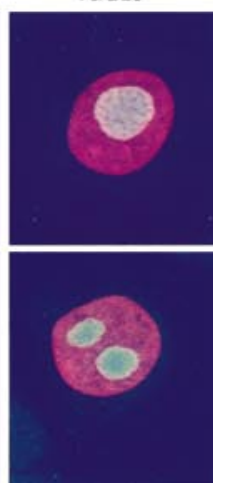


hindered by the insolubility of these proteins. In particular, this did not allow us to investigate the in vitro interaction between 41 and 75 or other possible interactions, for instance with RNA or DNA (data not shown). For the same reason, the analysis of their phosphorylation by different kinases was also not possible. Therefore, the tagged 41 and 75 constructs were transfected into eukaryotic cells in order to determine whether they could be analyzed after expression in vivo. Western blot analysis of cytoplasmic and nuclear fractions from COS cells transfected with these constructs demonstrated that both proteins are associated with the nuclear fraction and the size of these proteins (30 and $68 \mathrm{kDa}$ for 41 and 75, respectively) corresponded to that obtained after in vitro translation (Fig. 4). A similar result was obtained from transfection studies in Hela cells (data not shown). The extra minor bands most probably correspond to truncated products of the tagged 41 and 75 proteins. These observations therefore are in agreement with the sequence data which point out the presence of nuclear localization motifs in both proteins [2]. The availability of the tagged proteins allowed us to carry out immunofluorescence studies to determine the location of 41 and 75 within both untreated and IFN-treated transiently transfected HeLa cells.

\section{Localization of 41 and 75: Effect of Interferon}

Analysis of the localization of 41 tagged with $\mathrm{V} 5$ by immunofluorescence in transiently transfected HeLa cells revealed that 41 localizes to the nucleolus (Fig. $5 \mathrm{~A})$. Identical results were obtained in transiently transfected human 293 cells, in COS cells, and by using either the C-terminally Myc-tagged or the N-terminally HA-tagged 41 construct (data not shown). Treatment of the cells with IF $\alpha$ or IF $\gamma$ for $24 \mathrm{~h}$ resulted in a translocation of 41 to the periphery of the nucleolus (Fig. 5A).

75 mainly concentrates at the periphery of the nucleolus although, in contrast to 41 , it is also found in the nucleoplasm and there is little change in its location in response to IFN treatment (Fig. 5B). Cotransfection of 41 and 75 results in strong colocalization of 41 and 75 in the periphery of the nucleolus and appearance of a proportion of the 41 in the nucleoplasm (Fig. $5 C)$. It is striking to note here that, when observed alone, the localizations of 41 and 75 (left and middle parts of Fig. 5C, respectively), resemble those observed when each of them was transfected separately in IF Ntreated cells, with 41 being found at the periphery of the nucleolus (Figs. 5A and 5B). This strongly suggests that first the presence of 75 (as would be the case in interferon-treated cells) results in the translocation of 41 to the periphery of the nucleolus and that second, in spite of their forced overexpression, the transfected 41 and 75 proteins are able to present the same pattern of localization as the endogenous 41 and 75 proteins.

The 41 cDNA was initially isolated from a $\lambda$ gt11 expression library during a screen for PKR using PKRspecific polyclonal antibodies. Therefore we cotransfected HeLa cells with HA-tagged PKR and 41 or 75 to determine if these proteins colocalize with PKR. A tagged PKR construct was transfected into the cells instead of using anti-PKR antibodies against the IFNinduced endogenous protein to obtain a stronger signal. The majority of PKR was found, as expected, to localize to the cytoplasm and we found no evidence of colocalization of PKR with 41 or 75 (data not shown).

\section{1 and 75 Colocalize with Nucleolin but Not with \\ Fibrillarin or B23/ Nucleophosmin}

Since 41 and 75 concentrate in the nucleolus, we determined the location of these two proteins in relation to fibrillarin, B23/numatrin/nucleoplasmin, and nudeolin, which are abundant nucleolar proteins known to play important roles in ribosome biosynthesis.

As can be seen (Fig. 6) and as already reported [13], fibrillarin localizes to discrete spots within the nucleoIus which correspond to the sites of rRNA synthesis. In contrast, as described above, in untreated cells 41 localizes throughout the nucleolus (Fig. 6A). U pon treatment with interferon 41 translocates to the periphery of the nucleolus, where it surrounds the fibrillarin (Fig. $6 \mathrm{~A})$. Similarly 75, in both untreated and interferontreated cells, is found mainly at the periphery of the nucleolus where it, like 41, surrounds the fibrillarin (Fig. 6B). Thus 41/75 and fibrillarin do not colocalize.

A comparison of the localization of $41 / 75$ and B23 gives a similar result. Both in untreated and in interferon-treated cells B23 is found throughout the nucleolus (Figs. 6C and 6D). Although 41 and B23 have a similar location in untreated cells, upon treatment with interferon 41 translocates to the periphery of the nucleolus, where it surrounds the B23 and since 41 is induced by interferon it is likely that this is the localization which occurs naturally (Fig. 6C). In both untreated and interferon-treated cells, 75 is found mainly at the periphery of the nucleolus where it, like 41, surrounds the B23 (Fig. 6D). Thus, as in the case of fibrillarin, it is unlikely that $41 / 75$ colocalize with B23.

The localization of 41 and 75 was then compared with that of nucleolin. In untreated HeLa cells, 41 is found in the center of the nucleolus, with a ring of nucleolin surrounding it. On treatment with IFN, 41 translocates to this outer ring, and as a result 41 and nucleolin colocalize (Fig. 7A). The same experiment was also carried out in untreated or interferon-treated cells transfected with 75 , and similarly 75 was found to colocalize with nucleolin in the outer ring of the nucleolus (Fig. 7B). Cotransfection of 41 and 75 in both untreated and interferon-treated cells also results in 
colocalization with nucleolin at the periphery of the nucleolus (Fig. 7C).

\section{Effect of Actinomycin D on the Colocalization of 41/ 75 with Nucleolin}

In order to gain more information on the relationship among 41, 75, and other nucleolar proteins, we have studied the effect of actinomycin D on their localization. Treatment of cells with actinomycin $D$ is known to inhibit RNA synthesis, with high doses ( $5 \mu \mathrm{g} / \mathrm{ml}$ ) blocking the transcription of all RNA species, while low doses $(0.05 \mu \mathrm{g} / \mathrm{ml})$ preferentially block rRNA synthesis. Thus actinomycin treatment disrupts the function of the nucleolus but does not lead to its disappearance $[21,22]$. We first observed that both low $(0.05 \mu \mathrm{g} / \mathrm{ml})$ and high $(5 \mu \mathrm{g} / \mathrm{ml})$ concentrations of actinomycin D caused a dramatic redistribution of fibrillarin and B23 from the nucleoli to the nucleoplasm ( $\mathrm{Figs}$. 8A and 8B). A similar redistribution in Hela cells with low concentrations of actinomycin $\mathrm{D}$ has been previously reported for B23 [21]. In contrast low concentrations $(0.05 \mu \mathrm{g} /$ $\mathrm{ml}$ ) of actinomycin $\mathrm{D}$ have little effect on the localization of 41/75 and nucleolin (F igs. 8C and 8D)-compare with Fig. 6 for localization without actinomycin D), whereas high concentrations $(5 \mu \mathrm{g} / \mathrm{ml})$ cause the redistribution of 41/75 and nucleolin throughout the nucleoplasm (Figs. 8C and 8D). Therefore, these data strengthen the previous results showing that 41 and 75 colocalize with nucleolin.

\section{DISCUSSION}

In this study we have further characterized the two highly related IFN-induced nuclear phosphoproteins 41 and 75 that we have previously isolated. The 41 and 75 proteins are not homologous to any protein of known function. However, an interesting feature of these proteins is that their $\mathrm{C}$-terminal regions have significant sequence homology to those of SP100B, LYSP100, and SP140, members of the SP100 family of proteins (Fig. 9A). F urthermore, like 41 and 75, at least two members of this family, SP 100 and SP140, are induced by IFN $[3,4]$. The 41 and the 75 proteins also have homology with the KDWK or SAND domain in NUDR, previously reported as suppressin (Fig. 9B). This domain is found in a number of proteins, including the SP 100 family, DEAF-1, and the APECED polyglandular autoimmune protein AIRE-1 [6-9]. F urthermore, the 75 protein contains a $\mathrm{C} 4 \mathrm{HC} 3$ zinc finger domain near its $\mathrm{C}$-terminus (Fig. 9A). This domain, which has been named TTC (trithorax consensus) or PHD finger can be represented as C-X(1-2)-C-X(8-42)-C-X(2-4)-C-X(4)-H-X(2)-C-X(1146)-C-X(2)-C, where $X$ is any amino acid and the number in parentheses indicates the number of amino acids between the cysteines or histidine. A part from the cysteines and histidines, a number of hydrophobic/ aromatic amino acids are also highly conserved within this domain [10,11]. Similar domains are found in a number of nuclear proteins involved in the regulation of gene expression.

As the 41 and 75 proteins were found to be highly insoluble when expressed either in baculovirus or in $\mathrm{E}$. coli as GST fusion proteins, we have been unable as yet to obtain purified preparations of the recombinant proteins for the purpose of generating specific antisera, which are necessary for the detection of these proteins in IFN-treated cells. The attempt to use antipeptide antibodies raised against regions located in the nonhomologous C-terminal ends of 41 and 75 has also so far been unsuccessful. Those antibodies recognized mainly cytoplasmic proteins in Western blots and could neither detect in vitro translated 41 and 75 in immunoblots or by immunoprecipitation, nor detect overexpressed 41 and 75 proteins in immunofluorescence analysis (data not shown). This suggests that the regions of 41 and 75 chosen for preparation of antipeptide antibodies have low immunogenicity or that the sites are hidden under the conditions tested. As a result of this 41 and 75 were epitope tagged, which allowed us to study their cellular localization using confocal immunofluorescence.

The results from the confocal microscopy experiments demonstrate that as expected, since both 41 and 75 contain nuclear localization signals, both proteins are found in the nucleus. This is in agreement with analysis of cell extracts analyzed by Western blotting.

The 41 and 75 proteins both localize in the nucleoli. Unlike 41, 75 was also found throughout the nucleoplasm. On treatment with IF N, there is a translocation of 41 to the periphery of the nucleolus, while there is little change in the localization of 75 , which stays concentrated at the periphery of the nucleolus.

Cotransfection of 41 and 75 leads to a strong colocalization of both proteins in the periphery of the nucleolus and with the appearance of 41 in the nucleoplasm. The physiological significance of the colocalization of 41 and 75 to the outer ring of the nucleolus is not clear. However, since it occurs when the two proteins are simultaneously expressed in cells after cotransfection, it is also likely to occur when 41 and 75 are both induced after I F N treatment. We can therefore hypothesize that IF N treatment allows 41 and 75 to colocalize at the outer ring of the nucleolus, which is their physiological site of action. Since 41 and 75 localize to the nucleolus, which is the site for ribosome synthesis, and since they have homology to nucleic acid binding proteins and to proteins involved in the regulation of gene expression, it is plausible to suggest that 41 and 75 may play a role in ribosome biogenesis.

Apart from the microscopy results, which show that 41 and 75 colocalize, we have no evidence as yet that the two proteins interact directly with one another. Attempts to show direct interaction either by coimmu- 


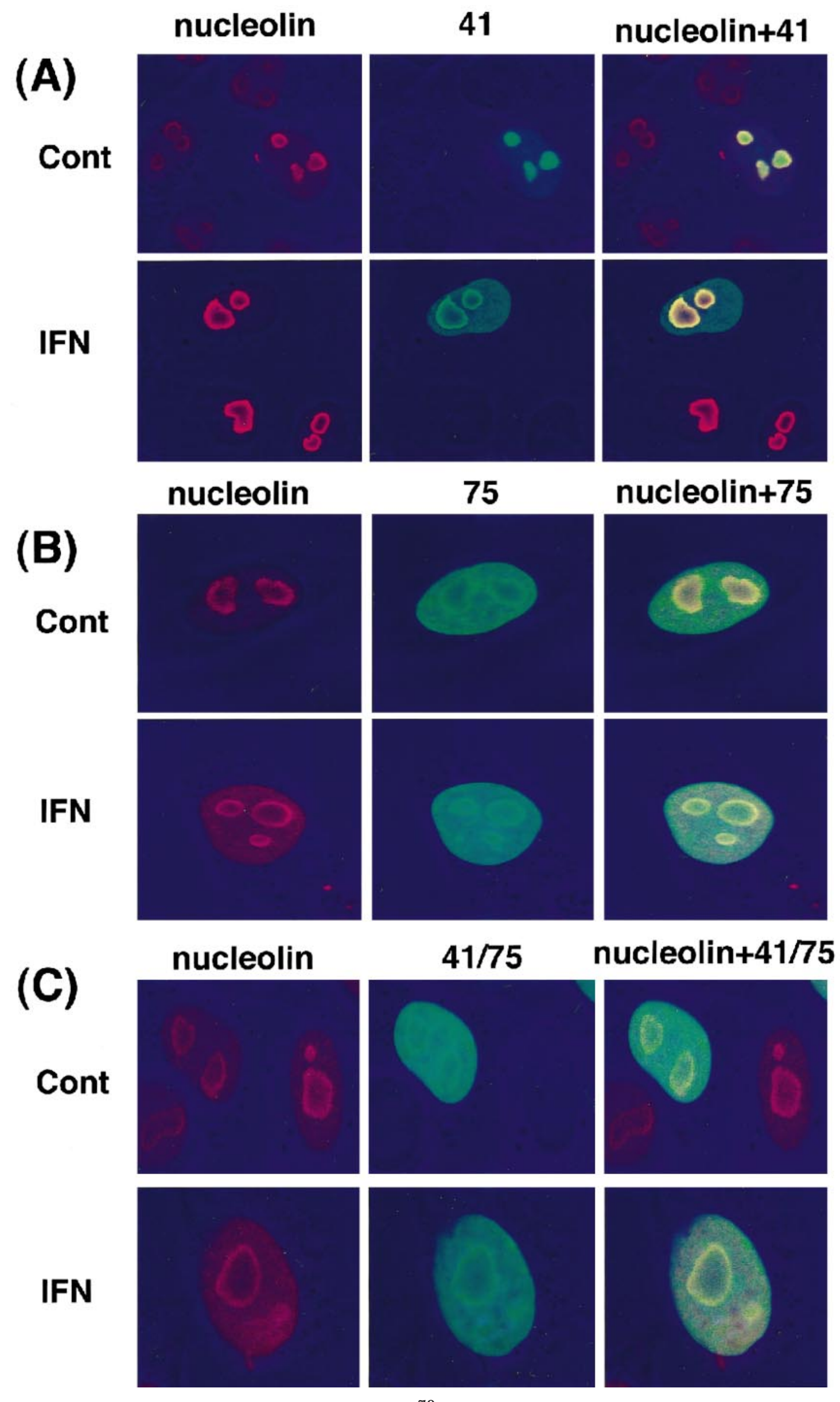


noprecipitation or by using the yeast two-hybrid system have so far been unsuccessful (data not shown). This may be due to technical problems, such as the insolubility of these proteins or their poor expression in yeast. However, it is also possible that 41 and 75 do not interact directly but that their colocalization is due to interaction with some other protein or structure, yet to be determined, within the nucleolus.

It should be noted that the nucleolar localization of 41 and 75 differs from that of the SP100 family of proteins, with which they share sequence homology and which are localized within nuclear bodies in the nucleoplasm $[3,4]$. The function of the nuclear bodies is unknown but since they contain several IFN-induced proteins it suggests that they may have a role in the interferon response. It has been shown that one of these IFN-induced nuclear body proteins, PML, can control cell proliferation and tumorigenesis and that it can confer resistance to infection by some types of viruses, suggesting that PML may have an important role in the antiviral and antiproliferative effects of interferon [23-25]. Roles for the other components of the nuclear body have yet to be established, although there is some evidence that SP100 may participate in activation of transcription of specific regions of the genome [26].

Nucleoli are structures which form around repetitive blocks of ribosomal DNA on chromosomal loci referred to as nucleolar organizers. This is where the ribosomal RNAs are transcribed, processed, and assembled from a $47 \mathrm{~S}$ precursor leading to the 28S, 18S, and 5.8S [27]. Nucleoli are also thought to have other roles, which include the processing and export of certain mRNAs and the processing of some tRNA precursors [28]. Although they assemble and disassemble during the cell cyde, nu-

FIG. 7. Comparison of the localization of $41 / 75$ and nucleolin in transiently transfected HeLa cells. Laser scanning confocal microscopy was carried out on untreated (Cont) or interferon-treated (IF N) $\mathrm{HeL}$ a cells which had been transiently transfected with HA41(A) or 75V5 (B) or HA41 and 75V5 (C). The cells were stained with the mouse anti-nucleolin monoclonal antibody $(A)$ or the rabbit polyclonal nucleolin antibody ( $\mathrm{B}$ and $\mathrm{C}$ ) and with rabbit anti-HA antibody (A), mouse anti-V5 antibody (B), or mouse anti-HA and anti-V5 antibody (C). This was followed by either anti-mouse IgG coupled to FITC (green fluorescence) and anti-rabbit IgG coupled to Texas red (red fluorescence) (A) or anti-rabbit IgG coupled to FITC (green fluorescence) and anti-mouse IgG coupled to Texas red (red fluorescence) (B and C). In each case red fluorescence (HA41/75V5) and green (nucleolin) were collected simultaneously and then separated digitally. Colocalization of proteins results in a merging of red and green fluorescence to produce a yellow image. The pictures show whole cells but in each case only the nucleolus or nucleus of the cell is stained.

FIG. 8. Effect of actinomycin $D$ on the colocalization of $41 / 75$ with nucleolin. Laser scanning confocal microscopy was carried out on HeLa cells which had been either mock transfected (A and $B$ ) or transiently transfected with HA41 (C) or 75V5 (D). The cells were then either left untreated (Cont) or treated with either $0.05 \mu \mathrm{g} / \mathrm{ml}$

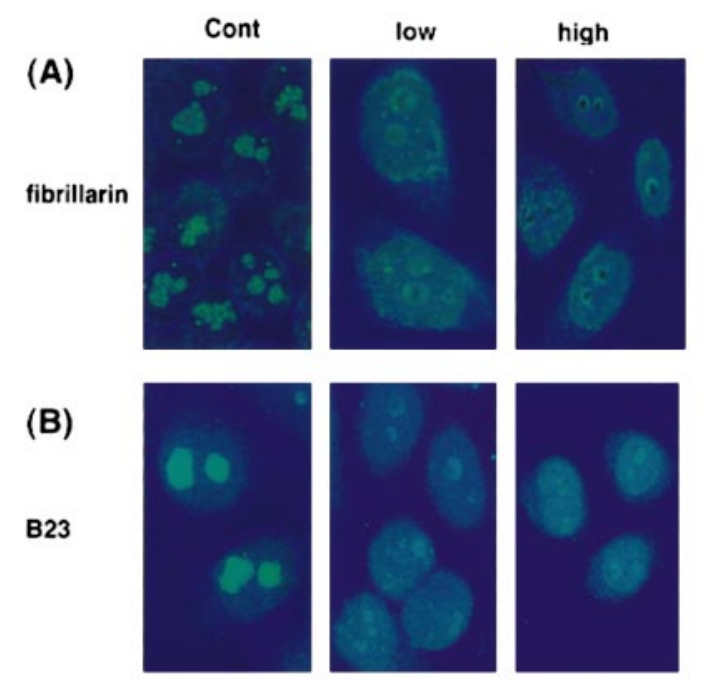

(C) nucleolin

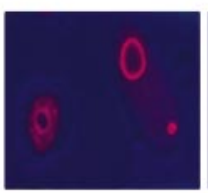

high

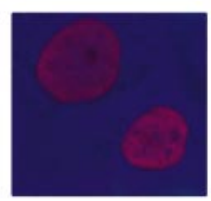

(D)

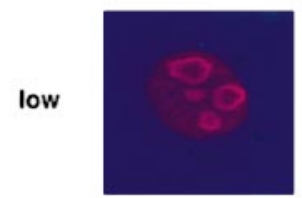

nucleolin
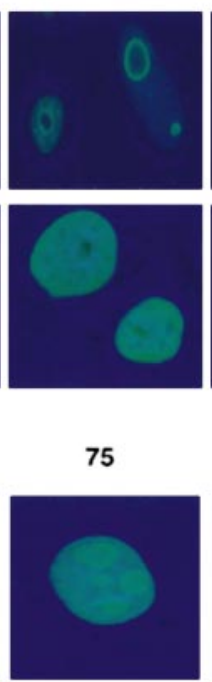

nucleolin +41
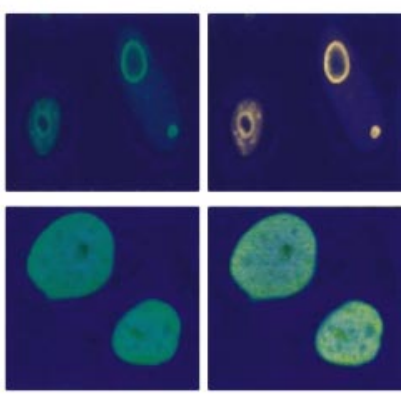

nucleolin +75

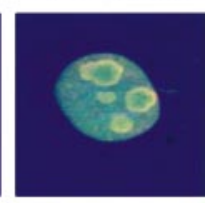

high
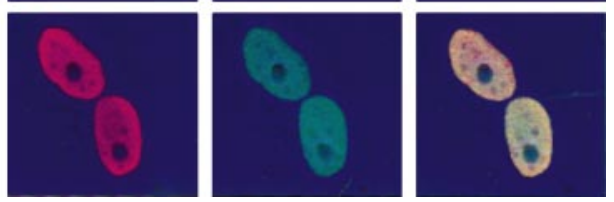

(low) or $5 \mu \mathrm{g} / \mathrm{ml}$ (high) actinomycin D as described under Materials and Methods. (A) In A and B the cells were stained with human anti-fibrillarin antibody followed by anti-human FITC (A) or with goat anti-B23 followed by anti-goat FITC (B). C and D show cells stained with the mouse anti-nucleolin monoclonal antibody (C) or the rabbit anti-nucleolin polyclonal antibody (D) and with either rabbit anti-HA antibody (C) or mouse anti-V5 antibody (D). This was followed by either anti-mouse IgG coupled to FITC (green fluorescence) and anti-rabbit IgG coupled to Texas red (red fluorescence) (C) or anti-rabbit I gG coupled to FITC (green fluorescence) and anti-mouse IgG coupled to Texas red (red fluorescence) (D). In each case red fluorescence (HA41 or 75V5) and green (nucleolin) were collected simultaneously and then separated digitally. Colocalization of proteins results in a merging of red and green fluorescence to produce a yellow image. The pictures show whole cells but in each case only the nucleolus or nucleus of the cell is stained. 


\begin{tabular}{ll}
\multicolumn{1}{c}{ A } & \\
41 & 137 \\
75 & 198 \\
LYSP100B & \\
SP100B & \\
SP140 &
\end{tabular}

SKRRFOKNIHRRG KPKSDTVDFHCSKLPVTCGEAKGILYKKKMK SKRRRFQKNIHRRG KPKSDTVDFHCSKLPVTCGEAKGILYKKKKMK SDRAAQKRVRSRASRKHKDETVDEKAPLLPVTCGGVKGILHKKKLQ PLKRRRKRGPRIPKDENINEKQSELPVTCGEVKGTLYKERFK SDRAAQKRVRSRASRKHKDETVDEKAPLLPVTCGGVKGILHKKKLQ

consensus

$\begin{array}{lllllllllll}S & R & K & R & K & F & \text { LPVTCG } & K G & \text { L } & K\end{array}$

41

75

LYSP 100B

SP100B

SP 140

HGSSVKCIRNEDGTWLTPNEFEVEGKGRNAKNWKRNIRCEGMTLGE HGSSVKCIRNEDGTWLTPNEFEVEGKGRNAKNWKRNIRCEGMTLGE QGILVKCIQTEDGKWFIPTEFEIKGGHARSKNWRLSVRCGGWPLRW QGTSKKCIQSEDKKWFTPREFEIEGDRGASKNWKLS IRCGGYTLKV QGILVKCIQTEDGKWFTPTEFEIKGG ARSKNWRLSVRCGGWPLRW

consensus

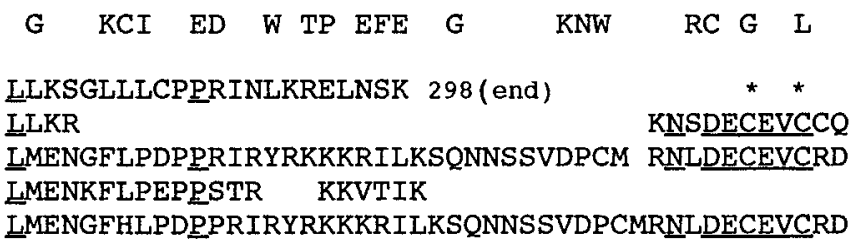

41

75

LYSPI00B

SP $100 B$

SP140

consensus

PHD consensus

75

LYSP $100 B$

SP 140

consensus

PHD consensus

\author{
75 \\ LYSP $100 B$ \\ SP140 \\ consensus
}

L

$\mathbf{P}$

N DECEVC

$\underline{\operatorname{Cxx}} \underline{\operatorname{CxX}}$

GGOLLCCGTCPRVFHEDCHIPPVEAKRMLWSCTFCRMKRSSGSOOC GGELFCCDTCSRVFHEDCH IPPVEAERTPWNCIFCRMKES S GSOOC GGELF CDTCSRVFHEDCH IPPVEAERTPWNCIFCRMKESPGSOOC

GG L C TC RVFHEDCHIPPVEA $R$ W C FCRMK $S$ GSQQC

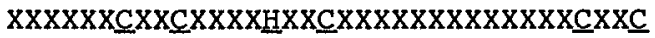

HHVSKTLEROMQPQDQLNVSSSS 371 (end)

CQESEVLEROMCPEEQLKCEFLL

CQESEVVLEROLKEPMWLDKIKKR

S LERQ

B

41
75

75

NUDR

consensus

41

75

NUDR

consensus
HCSKLPVTCGEAKGI LYKKKMKHGSSVKCIRNEDGTWLTPNEFEVE
HCSKLPVTCGEAKGILYKKKMKHGSSVKCIRNEDGTWLTPNEFEVE
YDSEIPVRCRNISGTLYKSRLGSGGRGRCIKQGE NWYSPTEEEAM

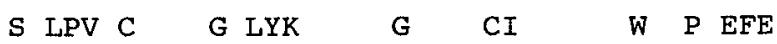

GKGRNAKNWKRNIRCEGMTLGELLK GKGRNAKNWKRNIRCEGMTLGELLK AGRASSKEDWKSIRYAGRPLQCLIQ

K WKR IR G L I

FIG. 9. (A) Alignment of the amino acid sequences of the 41 and 75 proteins with three members of the SP100 family: LYSP $100 B$, SP100B, and SP140. This alignment starts at residue 137 for 41 and residue 198 for 75 . The last residue shown for each of these proteins is their last codon. Residues common to all sequences are underlined and the resulting consensus sequence is shown. The PHD finger consensus sequence found in the C-terminal part of 75 and which is also found in LYSP100B and SP 140 is represented bel ow the consensus among 41, 75, and the SP100 family. No PHD finger was found in 41. Alignment of 75, referred to as HNPP1, with LYSP100-B and SP100B, has been previously reported $[4,10]$. (B) Alignment of the amino acid sequences of 41 and 75 with NUDR. This alignment takes place along 70 residues for each protein (aa 159 to 239 for 41 and aa 220 to 290 for 75 ). Identical residues are underlined and a consensus is shown.

cleoli have an organized proteinaceous architecture. The characterization of the nuclear proteins which are part of this architecture is important in understanding the role of the nucleolus. Among the nucleolar proteins which have been identified so far are the fibrillarin, the nud eolin, the nud eophosmin/B23/numatrin, the topoisomerase 
II, and the recently described Surf- 6 gene, a member of the Surfeit locus [29]. The interferon-induced phosphoproteins 41 and 75 can now be included in the family of nucleolar proteins, with both proteins being in strong association, although 75 is also found in the nucleoplasm. To date only one other interferon-induced protein, the $2 '-5^{\prime}$ oligoadenylate synthase-related protein p56, has been reported to be associated with the nudeolus [30]. However, it should be noted here that nucleolar nucleophosmin/B23/numatrin, which is also a phosphoprotein, has been found to interact with IRF-1, an activator of interferon genes and interferon-induced genes, and to inhibit its DNA binding and transactivation ([31]; see review [32]).

Since the nucleolus is a highly ordered structure, it seems likely that comparison of the localization of $41 / 75$ with other nucleolar proteins could give us an idea of their function. For this reason, we have compared their localization with the nucleolar proteins fibrillarin, B23/numatrin/nucleophosmin, and nucleolin. 41/75 do not colocalize with either fibrillarin, which is involved in all major posttranscriptional events in ribosome synthesis, or with B23/numatrin/nucleophosmin, which is involved in preribosomal particle assembly and as a shuttle receptor for the nucleoplasmic transport of ribosomal components [13, 31]. However, 41 and 75 do colocalize with nucleolin, one of the major RNA binding proteins of the nucleolus. This colocalization is not affected by low concentrations of actinomycin, which inhibits rRNA transcription and results in the redistribution of both fibrillarin and B23/numatrin/ nucleophosmin to the nucleoplasm.

Nucleolin has recently been shown to be involved in the first step of ribosomal RNA processing and is thought to have a role in the control of cell growth and to play a role in the regulation of rRNA gene transcription and the assembly of ribosomes [33-35]. It has been suggested that nucleolin plays an important role in coordinating rRNA processing and transcription so that the cell can efficiently regulate the production of ribosomes [35]. Therefore, our results suggest that 41 and 75 may function with nucleolin in the biosynthesis of ribosomes at a different stage than that of fibrillarin and B23 and we may hypothesize that 41 and 75 could play a role in the action of interferon, by regulating ribosomal RNA synthesis. This could be either a negative role, by inhibiting rRNA synthesis, or a positive role, by provoking rRNA synthesis, which would be convenient in allowing cell recovery. In addition, nucleolin or nucleolin containing complexes have recently been shown to be involved in poliovirus gene expression [36]. It would be of interest to determine the effect of the presence of 41 and 75 on this process as part of the antiviral actions of interferon.

At present there does not seem to be a link among 41, 75 , and PKR even though these proteins were initially isolated from a $\lambda$ gt11 expression library during a screen for this kinase using anti-PKR antibodies. Although extreme care was taken in preparing antibodies highly specific for PKR [17], the fact that a fragment of the 41 and 75 proteins could be recognized by these antibodies in the $\lambda$ gt11 screen indicates that either 41 was tightly bound to PKR during the preparation of PKR protein to make antibodies, and thus the PKR antibody is contaminated with one against 41 , or that PKR and 41 present a common epitope. The first possibility could be ruled out when we performed cotransfection studies of PKR and 41 to see if they colocalize. As mentioned under Results no such colocalization was observed, suggesting that 41 and PKR do not directly interact. In support of the second possibility, 41, 75, and PKR do share a short common sequence of six amino acids, which could account for the crossreactivity with the anti-PKR antibody [2]. Since both 41 and 75 present the characteristics of phosphoproteins, they might serve as substrates for PKR or lie downstream of the signaling pathways involving PKR and thus interactions between them would not be apparent using the laser scanning confocal microscopy technique. It is interesting to note that a proportion of cellular PKR has been reported to be in the nucleolus [37] and thus may interact in some way with 41/75. Studies to address the role of 41 and 75 in relation to PKR and to the antiviral and antiproliferative effects of interferon are ongoing.

G.I.W. is the recipient of an EMBO long-term fellowship. This work is funded in part by a grant from the L'Association Pour La Recherche Sur Le Cancer (ARC). We are very grateful to Emmanuelle Perret for help with the laser scanning confocal microscopy studies.

\section{REFERENCES}

1. Proud, C. G. (1995). PKR: A new name and new roles. Trends Biochem. Sci. 20, 241-246.

2. Kadereit, S., Gewert, D. R., Galabru, J ., Hovanessian, A. G., and Meurs, E. F. (1993). Molecular cloning of two new interferon-induced, highly related nuclear phosphoproteins. J . Biol. Chem. 268, 24432-24441.

3. Bloch, D. B., de la Monte, S. M., Guigaouri, P., Filippov, A., and Bloch, K. D. (1996). Identification and characterization of a leukocyte-specific component of the nuclear body. J . Biol. Chem. 271, 29198-29204.

4. Dent, A. L., Yewdell, J ., Puvion-Dutilleul, F., Koken, M. H. M., de The, H., and Staudt, L. M. (1996). LYSP100-associated nuclear domains ("LANDs"): A new class of sub-nuclear structures containing PML. Blood 88, 1423-1436.

5. Heery, D. M., Kalkhoven, E., Hoare, S., and Parker, M. G. (1997). A signature motif in transcriptional co-activators mediates binding to nuclear receptors. Nature 387, 733-736.

6. Gross, C. T., McGinnis, W. (1996). DEAF-1, a novel protein that binds an essential region in a Deformed response element. EMBO J . 15, 1961-1970.

7. Gibson, T. J ., Ramu, C., Gemund, C., and Aasland, R. (1998). The APECED polyglandular autoimmune syndrome protein, AIRE-1, contains the SAND domain and is probably a transcription factor. Trends Biochem. Sci. 23, 242-244. 
8. LeBoeuf, R. D., Ban, E. M. H., Green, M. M., Stone, A. S., Propst, S. M., Blalock, J . E., and Tauber, J . D. (1998). Molecular cloning, sequence analysis, expression and tissue distribution of Suppressin, a novel suppressor of cell cycle entry. J . Biol. Chem. 273, 361-368.

9. Huggenvik, J . I., Michelson, R. J ., Collard, M. W., Ziemba, A. J ., Gurley, P., and Mowen, K. A. (1998). Characterization of a nuclear deformed epidermal autoregulatory factor-1 (DEAF-1)related (NUDR) transcriptional regulator protein. Mol. Endocrinol. 12, 1619-1639.

10. Aasland, R., Gibson, T. J ., and Stewart, A. F. (1995). The PHD finger: Implications for chromatin-mediated transcriptional regulation. Trends Biochem. Sci. 20, 56-59.

11. Koken, M. H. M., Saib, A., and deThe, H. (1995). A C4HC3 zinc finger motif. C. R. Acad. Sci. Ser. III. Sci. Vie 318, 733-739.

12. Schmeichel, K. L., and Beckerle, M. C. (1994). The LIM domain is a modular protein-binding interface. Cell 79, 211-219.

13. Fomproix, N., Gébrane-Younes, J ., and Hernandez-Verdun, D. (1998). Effects of anti-fibrillarin antibodies on building of functional nucleoli at the end of mitosis. J . Cell Sci. 111, 359-372.

14. Coccia, E. M., Krust, B., Hovanessian, A. G. (1994). Specific inhibition of viral protein synthesis in HIV-infected cells in responseto interferon treatment. J . Biol. Chem. 269, 23087-23094.

15. Chomczynski, P. (1993). A reagent for the single-step simultaneous isolation of RNA, DNA and proteins from cell and tissue samples. Biotechniques 15, 532-534.

16. Sambrook, J ., Fritsch, E. F., and Maniatis, T. (1989). "Molecular Cloning: A Laboratory Manual," 2nd ed. CSHL Press.

17. Meurs, E. F., Watanabe, Y., Kadereit, S., Barber, G. N., Katze, M. G., Chong, K., Williams, B. R. G., and Hovanessian, A. G. (1992). Constitutive expression of human double-stranded RNA-activated p68 kinase in murine cells mediates phosphorylation of eucaryotic initiation factor 2 and partial resistance to encephalomyocarditis virus growth. J . Virol. 66, 5805-5814.

18. Weis, K., Rambaud, S., Carvalho, T., Cormo-Fonseca, M., Lamond, A., and Dejean, A. (1994). Retinoic acid regulates aberrant nuclear localization of PML-RAR alpha in acute promeolocytic leukemia cells. Cell 76, 345-356.

19. J efferies, H. B., Thomas, G. and Thomas, G. (1994). Elongation factor-1 alpha mRNA is selectively translated following mitogenic stimulation. J. Biol. Chem. 269, 4367- 4372.

20. Zhang, J ., Rosenburg, H. F., and Nei, M. (1998). Positive Darwinian selection after gene duplication in primate ribonuclease genes. Proc. Natl. Acad. Sci. USA 95, 3708-3713.

21. Yung, B. Y., Chang, F., Bor, A. M., and Lee, E. S. (1992). Schedule-dependent effects of two consecutive, divided, low doses of actinomycin D on translocation of protein B23, inhibition of cell growth and RNA synthesis in Hela cells. Int. J . Cancer 52, 317-322.

22. Scheer, U., Thiry, M., and Goessens, U. (1993). Structure, function and assembly of the nucleolus. TICB. 3, 236-241.

23. Mu, Z. M., Chin, K. V., Liu, J . H., Lozano, G., and Chang, K. S. (1994). PML, a growth suppressor disrupted in acute promyelocytic leukemia. Mol. Cell. Biol. 14, 6858-6867.
24. Wang, Z. G., Delva, L., Gaboli, M., Rivi, R., Giorgio, M., CordonCardo, C., Grosveld, F., and Pandolfi, P. P. (1998). Role of PML in cell growth and the retinoic acid pathway. Science 279, 1547-1551.

25. Chelbi-Alix, M. K., Qiugnon, F., Pelicano, L., Koken, M. H. M., and de Thé, H. (1998). Resistance to virus infection conferred by the interferon-induced promyelocytic leukemia protein. J . Virol. 72, 1043-1051.

26. Xie, K., Lambie, E. J., and Snyder, M. (1993). Nuclear dot antigens may specify transcriptional domains in the nucleus. Mol. Cell. Biol. 13, 6170-6179.

27. Lamond, A. In., and Earnshaw, W. C. (1998). Structure and function in the nucleus. Science 280, 547-553.

28. Pederson, T. (1998). The plurifunctional nucleolus. Nucleic Acids Res. 26, 3871-3876.

29. Magoulas, C., Zatsepina, O. V., J ordan, P. W. H., J ordan, E. G., and Fried, M. (1998). The SURF-6 protein is a component of the nucleolar matrix and has a high binding capacity for nucleic acids in vitro. Eur. J . Cell Biol. 75, 174-183.

30. Rebouillat, D., Marié, I., and Hovanessian, A. G. (1998). Molecular cloning and characterization of two related and interferon induced 56-kDa and 30kDa proteins similar to $2^{\prime}-5^{\prime}$ oligoadenylate synthase. Eur. J . Biochem. 257, 319-330.

31. Kondo, T., Minamino, N., Nagamura-I noue, T., Matsumoto, M., Taniguchi, T., and Tanaka, N. (1997). Identification and characterization of nucleophosmin/B23/numatrin which binds the anti-oncogenic transcription factor IRF-1 and manifests oncogenic activity. Oncogene 15, 1275-1281.

32. Nguyen, H., Hiscott, J ., and Pitha, P. M. (1997). The growing family of interferon Regulatory factors. Cytokine Growth Factors Rev. 8, 293-312.

33. Dickinson, L. A., and Kohwi-Shigematsu, T. (1995). Nucleolin is a matrix attachment region DNA-binding protein that specifically recognizes a region with high base-unpairing potential. Mol. Cell. Biol. 15, 456- 465.

34. Ghisolfi-Nieto, L., J oseph, G., Puvion-Dutilleul, F., Amalric, F., and Bouvet, P. (1996). Nucleolin is a sequence-specific RNAbinding protein: Characterization of targets on pre-ribosomal RNA. J. Mol. Biol. 260, 34-53.

35. Ginisty, H., Amalric, F., and Bouvet, P. (1998). Nucleolin functions in the first step of ribosomal RNA processing. EMBO J . 17, 1476-1486.

36. Waggoner, S., and Sarnow, P. (1998). Viral ribonucleoprotein complex formation and nucleolar-cytoplasmic relocalization of nucleolin in poliovirus infected cells. J . Virol. 72, 6699-6709.

37. J effrey, I. W., Kadereit, S., Meurs, E. F., Metzger, T., Bachmann, M., Schwemmle, M., Hovanessian, A. G., and Clemens, M. J. (1995). Nuclear localization of the interferon-inducible protein kinase PKR in human cells and transfected mouse cells. Exp. Cell Res. 218, 17-27. 